\title{
Effect of Organizational Climate upon the Job Satisfaction of Instructors Physical
}

\author{
Education (IPEs) \\ * Muhammad Safdar Luqman (Corresponding Author) \\ ** Dr. Syed Zia-ul-Islam \\ *** Ms. Afshan Jabeen, Senior Subject Specialist
}

\begin{abstract}
The main purpose of the current study was to examine the effect of Organizational Climate (OC) on Job Satisfaction (JS) of Instructors Physical Education working in Khyber Pakhtunkhwa. For this purpose, a sample of 112 Instructors was selected through a stratified random sampling method. An adapted organizational climate and job satisfaction scale was used for data collection. Pearson product Correlation and regression analysis were applied as inferential statistics with the help of SPSS version 20. The result of the study depicts that organizational climate plays a significant role in the job satisfaction of physical education teachers. A supportive and conducive climate enhances the satisfaction level of physical education teachers.
\end{abstract}

Keywords: Organizational Climate (OC), Job Satisfaction (Js), Instructor Physical Education (IPEs) Introduction

Job Satisfaction occupies a vital role in terms of human resource management. The importance of job satisfaction has two aspects. The first aspect includes it retains the employees in the organization whereas the second aspect includes it enhances the level of performance. On the other hand, the organizational climate has a key position that influences everyone who works in the organization. It affects the individual's behavior and attitude towards the job. So, the environment has been considered as a key factor that influences the employee's behavior and attitude towards work (Khalid, Irshad \& Mahmood, 2012). Organizational climate refers to the perceptions of individuals towards the climate of the organization and one's perception is often argued as to influence the behavior of an individual (Danish, Daraz, \& Ali, 2015). It is observed that happy and satisfied employees performed better as compared to a dissatisfied one. Such observation is strengthened through the results of different empirical researches. The relationship between organizational climate and Job Satisfaction is viewed and discussed in the literature from the last two decades. The present paper filled the gap that how organizational climate link with the job satisfaction of the IPEs. Instructors' physical Education (IPEs) has a key position in higher secondary schools. They maintain the school discipline along with other teachers as well as engage in the teaching-learning process. The current study is helpful for administrators to know the current scenario of climate developed in higher secondary schools. School Principals get benefit from this study to establish a healthy and conducive environment with elements of mutual respect, the good relationship among staff members, reward system, highly structured communication, teamwork, and good leadership. Such elements highlight the importance of organizational climate which enhances the satisfaction level of IPEs. The current study was conducted to examine the effect of organizational climate upon job satisfaction of IPEs working in Higher Secondary Schools in Southern Districts of Khyber Pakhtunkhwa. The objectives of the study areas:

1. To investigate the effect of organizational climate upon job satisfaction of IPEs working in Higher Secondary Schools.

2. To examine the Different dimensions of OC on the IPEs Job Satisfaction.

\footnotetext{
* Department of Sports Sciences and Physical Education, Gomal University, Dera Ismail Khan, Khyber Pakhtunkhwa (K.P) Pakistan Email: safdarkhan821@gmail.com

** Department of Sports Sciences and Physical Education, Gomal University, Dera Ismail Khan, Khyber Pakhtunkhwa (K.P) Pakistan

*** Education Department Punjab, Lahore
} 


\section{Literature Review}

Organizational climate has been viewed as a popular concept for decades. Researchers used and conducted researches on the subject of organizational climate in different fields such as industries, health, banking, and education sector (Mehr, Emadi, Cheraghian, Roshani \& Behzadi, 2012). Organizational climate is generally expressed as the perception of individuals towards his work or job (Chang \& Lin, 2015). Zamini et al. (2011) refers to the organizational climate as the views of employees towards the organization's policies, established norms, and organizational procedures. Organizational climate is measured by numerous components namely role clarity, community, respect, reward structure, conflict management and teamwork, and support (Osibanjo \& Adeniji, 2013). The positive and healthy environment has a significant role in the satisfaction level of employees which influences the teaching-learning process. Therefore, school principals should focus to develop the congenial environment to enhance the job performance and job satisfaction of the teachers. It is not possible to achieve organizational objectives without a healthy climate (Lund, 2003). Teachers provide better results in a better school climate.

Job Satisfaction refers to the individual personal judgment about the situation present in the job (Khalid et al, 2012). According to Mansoor and Tayyub (2010), Job satisfaction is a favorable emotional condition that comes from the individual's job experience. According to Rahimić (2013) Job satisfaction refers to the feeling of the individual about the environment related to the job. Tsai (2011) elaborated that job satisfaction is the emotional condition in which employee feel that how he or she is comfortable in the organization. Many empirical studies have been conducted in which job satisfaction linked with many factors such as reward system, supervision, job performance, and organizational climate. However, researchers focused on the relationship between organizational climate and job satisfaction (Danish et al., 2015). Teachers with dissatisfy feeling about his job cannot perform well in school. Therefore, a satisfied teacher teaches effectively as compared to a dissatisfied teacher (Zafar \& Vikramjeet, 2017). Furthermore, satisfied teachers are more committed and motivated than less satisfied teachers. Job satisfaction improves the productivity of the organization, produced high morale, and increases the working skills of the personnel.

\section{Research Questions}

1. Whether the effect of Organizational Climate (OC) on Job Satisfaction (JS) of Instructors Physical Education is statistically significant?

2. Whether the impact of various components of OC on the JS of Instructors Physical Education is statistically significant?

\section{Theoretical Framework}

A considerable amount of empirical studies had investigated the effect of Organizational Climate (OC) on Job Satisfaction (JS). Behzadi et al. (2012) found that there is a positive correlation between OC and JS among the physical instructors. Khalid ET. al. (2012) revealed that the organizational climate significantly influences job satisfaction. Adeniji (2011) depicts that a positive organizational climate may enhance the teachers' satisfaction level. Teachers produce desirable objectives and innovative ideas in a supportive and healthy environment. Mansoor and Tayib (2010) conducted a study regarding the association between different elements of OC and Job Satisfaction. The result of the study indicates that respect, promotion and opportunities, teamwork, supervision, and effective communication have a significant influence on job satisfaction. Teachers are satisfied in such an organization in which there is a respectful workplace, reward culture, shared objectives, supervision, and teamwork. Following research hypotheses are generated based on the above discussion:-

$\mathrm{H}_{1}$ : Effect of Organizational Climate (OC) on Job Satisfaction (JS) of Instructors Physical Education is statistically significant.

$\mathrm{H}_{2}$ : Impact of various components of OC on JS of Instructors Physical Education is statistically significant. 


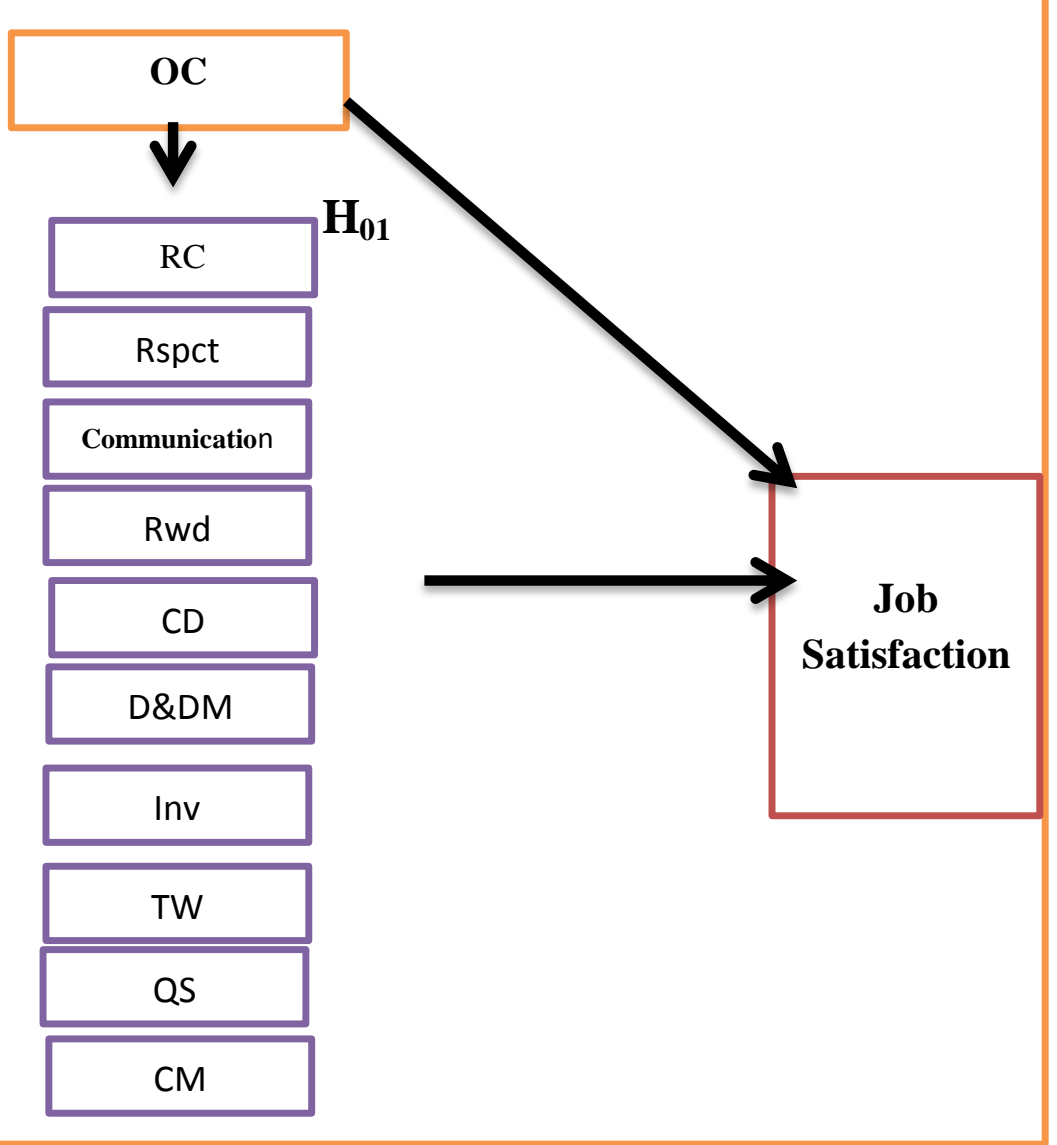

According to Cooper and Schindler (2003) positivist philosophy refers to the view that factual knowledge can be obtained through observation. The role of the researcher in this study is confined to data collection and statistical analysis. Furthermore, the survey research design was employed. Survey research design is a type of quantitative research method in which data is collected from the individuals on some social phenomenon (Dooley, 2003)

The study was conducted in three divisions of Khyber Pakhtunkhwa which include D.I.Khan, Hazara, and Peshawar. There are 156 IPEs (91 male and 65 female) working as Instructors Physical Education in different higher secondary schools (Educational Management Information System [EMIS], 2019). A sample of 112 IPEs (71 male and 41 female) participated in the study and a stratified sampling method was selected. Further proportionate stratified random technique was applied. The strata were based on the male and female populations. Following Yamane, (1967) mathematical formula was applied to determine the sample size.

Table 1 Sample Size

$$
n=\frac{N}{1+N e^{2}}=\frac{156}{1+156 * .05^{2}}=112
$$

\begin{tabular}{lllll}
\hline Participants & Sex & Population & Percentage & Required sample \\
\hline IPEs & Male & 91 & $58 \%$ & $112 * 63 \%=71$ \\
& Female & 65 & $42 \%$ & $112 * 37 \%=41$ \\
Total & ----- & 156 & 100 & 112 \\
\hline
\end{tabular}

Further, an adapted research tool was used which was constructed by Furnham and Goodstein (1997) whereas the Job Satisfaction scale was constructed by Mehrotra (2005). Validation of the research tool is important in social research. Therefore, a pilot study was done and the questionnaire was distributed to 12 experts (Associate professors and Assistant Professor and Principals) for validation. For validation Content Validity Ratio (CVR) was applied. According to Lindell and Brandt (1999), the acceptable range for each item falls 0.3 to 1.0. Experts were requested to assess every item 
based on three-point Likert scale (Appropriate=1, not Appropriate=2, Ambiguous=3) Given Formula is used:-

Table 2 Content Validity Ratio (CVR) Score

$$
\mathrm{CVR}=\left[\left(E-\left(\frac{N}{2}\right) /\left(\frac{N}{2}\right)\right]\right]
$$

\begin{tabular}{|c|c|c|c|}
\hline Face-sets & No. of questions & IOC & Result \\
\hline \multirow[t]{2}{*}{$\begin{array}{l}\text { Organizational } \\
\text { Climate }\end{array}$} & 44 & $\begin{array}{c}0.7,0.3,0.4,0.4,0.5,0.6,0.6, \\
0.7,0.6,0.6,0.8,0.4,0.4,0.3, \\
0.4,0.4,0.4,0.5,0.3,0.8,0.3, \\
0.4,0.3,0.4,0.4,0.5,0.4,0.4, \\
0.5,0.4,0.4,0.6,0.5,0.5,0.5, \\
0.5,0.5,0.5,0,6,0.5,0.5\end{array}$ & Retained all items \\
\hline & 41 & $\begin{array}{l}0.8,0.6,0.6,0.5,0.5,0.6,0.6, \\
0.5,0.5,0.5,0.5,0.5,0.5,0.5, \\
0.5,0.5,0.3,0.6,0.7,0.5,0.7, \\
0.7,0.7,0.6,0.8,0.6,0.6,0.7, \\
0.7,0.8,0.4,0.7,0.5,0.3,0.5, \\
0.5,0.5,0.5,0.5,0.5,0.5,0.5, \\
0.5,0.6,0.5,0.5,0.5,0.4,0.4\end{array}$ & Retained all items \\
\hline
\end{tabular}

Table 2 shows that the score of every item above the cutoff criteria, so every item retained in the questionnaire. The internal consistency of the questionnaire is estimated through Cronbach's Alpha. The result of the Cronbach's Alpha is measured through computer software SPSS (Version, 21.0). The following table shows the reliability score:-

Table 3 Reliability Score

\begin{tabular}{lll}
\hline Scale & No. of Item & Cronbach' Alpha Score \\
\hline OC & 44 & .902 \\
JS & 39 & .923 \\
\hline
\end{tabular}

The researcher personally collected the data in September 2019 with ethical considerations and feed into data matrix SPSS. According to the nature of the study, Pearson Product Correlation and Regression Analysis were applied to test the research hypotheses.

Result and Discussion

Table 4 Relationship between Organizational Climate (OC) and Job Satisfaction (JS)

\begin{tabular}{llll}
\hline & & Organization Climate & Job Satisfaction \\
\hline Organizational Climate & Pearson Correlation & 1 & $.693^{* *}$ \\
& P-value & & .001 \\
& $\mathrm{~N}$ & 156 & 156 \\
\hline
\end{tabular}

Table 4 indicates the relationship between OC and JS using Pearson Product Correlation. The table reveals that there is a positive correlation between OC and JS $\left(r=693^{* * *}\right)$. The table depicts the relationship between the variable found significant $(\mathrm{P}=.001<.05)$.

Table 5 Regression model regarding the effect of Organizational climate (OC) and Job Satisfaction (JS).

\begin{tabular}{lllllll}
\hline IV & $\mathrm{R}$ & $\mathrm{R}^{2}$ & Adj R $^{2}$ & $\mathrm{~B}$ & Sig & Durban Watson \\
\hline OC & .693 & .481 & .471 & .779 & .000 & 2.01 \\
\hline
\end{tabular}

Table 5 shows the regression output regarding the effect of OC on JS. The table is selfexplanatory which shows that $\mathrm{R}^{2}=481$ which illustrates $48 \%$ change occurs in DV (JS) due to IV (OC). The result also shows that the effect of OC on JS is found significant $(\mathrm{P}=.000<.05)$. Positive Beta score indicates that if one unit increases in IV (OC) then .779 unit (S.D) increase in DV (JS). There is no autocorrelation (2.01) found between the independent variable (OC) and the Dependent variable (JS). 
Table 6 Correlation Analysis Matric of Organizational Climate and Job performance

\begin{tabular}{|c|c|c|c|c|c|c|c|c|c|c|c|}
\hline & RC & Rspt & Com & Rwd & CD & PDM & $\overline{\text { Inv }}$ & TW & $\overline{\mathbf{Q S}}$ & $\overline{\mathrm{CM}}$ & JS \\
\hline RC & 1 & & & & & & & & & & \\
\hline Rspt & $\begin{array}{l}.669 \\
* *\end{array}$ & 1 & & & & & & & & & \\
\hline Com & $\begin{array}{l}.721 \\
* *\end{array}$ & $.876_{*}^{*}$ & 1 & & & & & & & & \\
\hline Rwd & $\begin{array}{l}.821 \\
* *\end{array}$ & $.982^{*}$ & $.592_{*}^{*}$ & 1 & & & & & & & \\
\hline CD & $\begin{array}{l}.723 \\
* *\end{array}$ & $.875_{*}^{*}$ & $\begin{array}{r}.679^{*} \\
*\end{array}$ & .98 & 1 & & & & & & \\
\hline PDM & $\begin{array}{l}.890 \\
* *\end{array}$ & $\begin{array}{r}.789^{*} \\
*\end{array}$ & $.590^{*}$ & $9^{* * *}$ & $.762^{\text {** }}$ & 1 & & & & & \\
\hline Inv & $\begin{array}{l}.762 \\
* *\end{array}$ & $.761^{*}$ & $.652^{*}$ & $\begin{array}{l}.67 \\
2^{* *}\end{array}$ & $.879^{\text {*** }}$ & $.433^{*}$ & 1 & & & & \\
\hline TW & $\begin{array}{l}.678 \\
* *\end{array}$ & $.678_{*}^{*}$ & $.768_{*}^{*}$ & $5^{.88}$ & $.678^{* * *}$ & $.870_{*}^{*}$ & .78 & 1 & & & \\
\hline QS & $\begin{array}{l}.768 \\
* *\end{array}$ & $.672^{*}$ & $.765^{*}$ & .56 & $.789^{\text {*** }}$ & $.879^{*}$ & $\begin{array}{l}.78 \\
9^{* * *}\end{array}$ & .879 & 1 & & \\
\hline CM & $\begin{array}{l}.661 \\
* *\end{array}$ & $.763^{*}$ & $.654^{*}$ & .76 & $.546^{* * *}$ & $.780^{*}$ & $\begin{array}{l}.89 \\
7^{* *}\end{array}$ & .864 & .876 & 1 & \\
\hline JS & $\begin{array}{l}.667 \\
* *\end{array}$ & $.457 * *$ & $\begin{array}{l}.872 * \\
*\end{array}$ & $\begin{array}{l}.789 * \\
*\end{array}$ & $.678 * *$ & $\begin{array}{l}.879 * \\
*\end{array}$ & $\begin{array}{l}.456 \\
* *\end{array}$ & $\begin{array}{l}.875^{*} \\
*\end{array}$ & $\begin{array}{l}.876 \\
* *\end{array}$ & $.873^{* *}$ & 1 \\
\hline
\end{tabular}

sRC=Role Clarity, Rspt=Respect, $\mathrm{CD}=$ Career Development, PDM=Planning \& Decision Making, Inv=Innovation, QS=Quality Service, CM=Conflict Management, JS=Job Satisfaction

Table 6 shows the correlation matrix between ten (10) components of OC and JS. The result shows +ve relationship between Role clarity RC and JS ( $\left.\mathrm{r}=.667^{* *}\right)$, Respect and JS ( $\left.\mathrm{r}=.457^{* *}\right)$, CD and JS $\left(\mathrm{r}=.678^{* *}\right)$, PDM and JS ( $\left.\mathrm{r}=.879^{* *}\right)$, TM and JS $\left(\mathrm{r}=.456^{* *}\right)$, QS and JS $\left(\mathrm{r}=.875^{* *}\right), \mathrm{CM}$ and JS $(\mathrm{r}=.873 * *)$.

Table 7 Regression Model regarding Effect of Ten (10) components of OC on JS.

\begin{tabular}{llllll}
\hline IV & $\mathrm{R}$ & $\mathrm{R}^{2}$ & Adj R $^{2}$ & $\mathrm{Sig}$ & Durban Watson \\
\hline $\mathrm{OC}$ & .575 & .392 & .331 & .000 & 1.79 \\
\hline
\end{tabular}

Table 7 shows the regression output regarding the effect of 10 components of OC on JS. The table is self-explanatory which shows that $\mathrm{R}^{2}=.392$ which illustrates $39 \%$ change occurs in DV (JS) due to IV (OC). The result also shows that the effect of OC on JS is found significant $(\mathrm{P}=.000<.05)$. There is no autocorrelation (2.01) found between the independent variable (OC) and the Dependent variable (JS).

Table 8 Co-efficient

\begin{tabular}{|c|c|c|c|c|c|c|c|}
\hline \multirow[t]{2}{*}{ Model } & \multicolumn{2}{|c|}{$\begin{array}{l}\text { Unstandardized } \\
\text { Coefficient } \\
\end{array}$} & \multirow{2}{*}{$\begin{array}{r}\begin{array}{l}\text { Standardize } \\
\text { d Coefficient }\end{array} \\
\text { B }\end{array}$} & \multirow[t]{2}{*}{$\mathbf{t}$} & \multirow[t]{2}{*}{ Sig } & \multicolumn{2}{|c|}{$\begin{array}{l}\text { Collinearity } \\
\text { Statistics }\end{array}$} \\
\hline & B & Std.Error & & & & VIP & $\begin{array}{l}\text { Toleran } \\
\text { ce }\end{array}$ \\
\hline (Constant) & $\begin{array}{r}2.33 \\
7\end{array}$ & .494 & & $\begin{array}{r}4.73 \\
4\end{array}$ & $\begin{array}{r}.00 \\
0\end{array}$ & & \\
\hline $\mathrm{RC}$ & .421 & .116 & .019 & .174 & $\begin{array}{r}.86 \\
2\end{array}$ & $\begin{array}{r}.57 \\
2\end{array}$ & 1.748 \\
\hline Respect & .653 & .129 & -.059 & -.416 & $\begin{array}{r}.67 \\
9\end{array}$ & $\begin{array}{r}.31 \\
7\end{array}$ & 3.156 \\
\hline Communication & .490 & .119 & -.147 & -.753 & $\begin{array}{r}.45 \\
3\end{array}$ & $\begin{array}{r}.17 \\
0\end{array}$ & 5.883 \\
\hline Reward system & .108 & .082 & -.167 & 1.31 & $\begin{array}{r}.19 \\
3\end{array}$ & $\begin{array}{r}.40 \\
2\end{array}$ & 2.485 \\
\hline
\end{tabular}




\begin{tabular}{lccrrrrr}
\hline & .167 & .073 & .288 & 2.27 & .02 & .40 & 2.480 \\
CD & .167 & & 0 & 5 & 3 & \\
PlngDmaking & .137 & .114 & .204 & 1.20 & .23 & .22 & 4.427 \\
& & & & 2 & 2 & 6 & \\
Innovation & .048 & .073 & .083 & .654 & .51 & .40 & 2.476 \\
& & & & & 4 & 4 & \\
Teamwork & .217 & .110 & .009 & .068 & .94 & .33 & 2.984 \\
& & & & & 6 & 5 & \\
Service & .109 & .090 & .177 & 1.21 & .22 & .30 & 3.259 \\
& .171 & .084 & .231 & 2.03 & .04 & .50 & 1.984 \\
CManagment & & & & 3 & 5 & 4 & \\
\hline
\end{tabular}

Table 8 indicates the regression coefficient of the independent variable (OC) and the dependent variable (JS). The above result is self-explanatory and shows that the beta value of each IV produced some degree of influence on DV (JS). The table depicts that change in JS due to different dimensions of OC is following, Role clarity $(\beta=412)$, respect $(\beta=563)$, Communication $(\beta=490)$, reward structure $(\beta=.108)$, Career development $(\beta=.167)$, Planning and Decision making $(\beta=.137)$, Innovation $(\beta=.048)$, Teamwork and support $(\beta=.217)$, Quality service $(\beta=.109)$ and Conflict Management $(\beta=171$.). The last two columns showing the multicollinearity value which is the basic assumption for multiple regression techniques. There two important values in multicollinearity i: e Variance Inflation Factor (VIF) and Tolerance. According to Gerbing (2014), there is no multicollinearity issue if the value of VIF is under 5 and Tolerance above 0.20 . The table clearly shows that all the value of VIF and Tolerance falls in the acceptable range.

\section{Discussion}

Job Satisfaction is a key necessity for organizational climate and assumes an essential job in upgrading the efficiency of the performance of workers, level of responsibility, and boosting the morale of the employees. Various investigations have discovered that a positive atmosphere in the association produces fulfillment among the employees. The present study aimed to examine the influence of organizational climate (OC) on Job Satisfaction (JS) of Instructor Physical Education (IPEs) working in Higher secondary schools in three divisions of Khyber Pakhtunkhwa. The result of the study shows that there is a positive relationship between OC and JS. The result of the study is supported by Rahimić (2013). They concluded that job satisfaction increases among employees due to many factors and organizational climate is one of the leading factors. The conducive and supportive climate brings a high level of motivation among employees which increases the productivity of the organization. The result of the study indicates that different dimensions of OC have a significant impact on Job Satisfaction. The same result was mentioned by Tsai (2011) and Jyoti (2013). They found that different dimensions have a significant impact on job satisfaction. Moreover, they found that the reward system brings positive change in the employees' behavior which produces satisfaction among employees. Danish et al. (2015) found that organizational performance depends upon the satisfaction of employees and the satisfaction of employees depends upon teamwork.

\section{Conclusion}

The result of the study concluded there is a positive relationship between the organizational climate and job satisfaction. A supportive and healthy climate causes higher satisfaction among employees. The present study concluded that the organizational climate is one of the important elements that the school principal must consider to enhance the satisfaction level of the Instructors Physical Education. Moreover, different components of $\mathrm{OC}$ which include respect, role clarity, effective communication, reward system, teamwork, and conflict management play a vital role to boost the satisfaction of employees.

\section{Recommendations and Research Implication}

The study concluded that there is a positive relationship between organizational climate and job satisfaction. Therefore, it is recommended that School Principals may develop a conducive climate in the school to maximize the satisfaction level of Physical education teachers. For this purpose, responsibilities may be assigned to instructors' physical education according to the nature of the job. 
The school principal may create teamwork to accomplish the educational objectives. Furthermore, it is recommended that the Government may introduce programs to award incentives that perform well which will enhance the satisfaction of instructors' physical education.

The study has great implications in the educational sector. The present study provides empirical evidence regarding the influence of organizational climate on job satisfaction of instructors' physical education. There are very limited researches that have been conducted on such a topic. The study has a practical implication for school principals and apex bodies of elementary and secondary education, Khyber Pakhtunkhwa. The importance of OC is vital to enhance the job satisfaction of instructors' physical education.

\section{References}

Adeniji, A., A. (2011). Organizational climate and job satisfaction among academic staff in some selected private universities in southwest Nigeria (Doctoral dissertation, Covenant University).

Amos, E. A., \& Weathington, B. L. (2008). An analysis of the relationship between employee Organization value congruence and employee attitudes. The journal of psychology, 142(6), 615-632.

Bhatti, K., \& Qureshi, T. (2007). Impact of employee participation on job satisfaction, employee commitment, and employee productivity. International Review of Business Research Papers, $3(2), 54-68$.

Chang \& Lin, (2015). The role of organizational culture in the knowledge management process. Journal of Knowledge Management, 19(3), 433-455.

Cooper, D.R., \& Schindler, P.S. (2003). Business Research Methods (8th Ed.). Boston, MA: McGraw-Hill Irwin.

Danish, R., Draz, U., \& Ali, Y. (2015) Impact of Organizational Climate on Job Satisfaction and Organizational Commitment in Education Sector of Pakistan, American Journal of Mobile Systems, Applications, and Service, 2(1).

Dooley, D. (2003). Social Research Methods, (3rd Ed). Asoke K Ghosh, Prentice-Hall of India Private Limited. New Delhi - 110001.

Education Management Information system [EMIS]. Annual Statistical Report. (2018). [cited 2019 May 29]. Available from: https://www.kpese.gov.pk

Furnham, A., \& Goodstein, L. D. (1997). The organizational climate questionnaire (OCQ). AnnualSan Diego-Pfeiffer And Company, 2(1), 163-182.

Gerbing, D. (2014). Collinearity. School of Business Administration at Portland State University.

Jyoti, J. (2013), Impact of Organizational Climate on Job Satisfaction, Job Commitment and Intention to Leave: An Empirical Model. Journal of Business Theory and Practice, 2(2)

Khalid, S., Irshad, M. Z., \& Mahmood, B. (2012). Job satisfaction among academic staff: a comparative analysis between public and private sector universities of Punjab, Pakistan. International Journal of Business and Management, 7(1), 126-136

Lindell, M. K., \& Brandt, C. J. (1999). Assessing inter-rater agreement on the job relevance of a test: A comparison of CVI, T, rWG (J)\}, and r* WG (J)\} indexes. Journal of Applied Psychology, 84(4), 640.

Lund B., (2003) "Organizational culture and job satisfaction", Emerald 18.

Mansoor, M. \& Tayib, M. (2010), An empirical examination of organizational culture, job stress, job satisfaction within the indirect tax administration in Malaysia, International Journal of Business and Social Sciences, 01(01): 81-95.

Mehr, S. K., Emadi, S., Cheraghian, H., Roshani, F., \& Behzadi, F. (2012). Relationship between job satisfaction and organizational culture in staff and experts of physical education offices of Mazandaran Province. European Journal of Experimental Biology, 2(4), 1029-1033.

Mehrotra, A. (2005). Leadership styles of principals. India: Mittal Publications.

Osibanjo, A. O., \& Adeniji, A. A. (2013). Impact of organizational culture on human resource practices: a study of selected Nigerian private universities. Journal of Competitiveness, 5(4), 115-133.

Rahimić, Z. (2013). Influence of Organizational Climate on Job Satisfaction in Bosnia and Herzegovina Companies. International Business Research 6(3): 129-139. 
Tsai, Y. (2011). "Relationship between Organizational Culture, Leadership Behavior and Job Satisfaction”, BMC Health Services Research, 11, pp. 98

Yamane, T. (1967). Elementary Sampling Theory, Prentice-Hall Inc., Englewood Cliffs, NJ

Zafar .S. and Vikramjeet (2017). "Impact of Prevailing HRM Practices on Job Satisfaction: A Comparative Study of Public and Private Higher Educational Institutions in India, International Journal of Business and Management; Vol. 12, No. 1; pg. 178-187.

Zamini S. ET. al. (2011), The relationship between organizational culture and job burnout among the professors and employees in the University of Tabriz, Procedia - Social and Behavioral Sciences, 30 pp- 1964 -1968.ap 